\title{
Land use/land cover changes and regional climate over the Loess Plateau during 2001-2009. Part II: interrelationship from observations
}

\author{
Xingang Fan • Zhuguo Ma • Qing Yang • Yunhuan Han • \\ Rezaul Mahmood
}

Received: 9 April 2013 / Accepted: 20 January 2014 / Published online: 13 February 2014

C The Author(s) 2014. This article is published with open access at Springerlink.com

\begin{abstract}
Afforestation efforts in China resulted in significant changes in vegetation coverage over the Loess Plateau during 2001-2009. While regional climate conditions dominate the distribution of major vegetation types, human activities, primarily afforestation/reforestation and the resultant land use/land cover (LULC) changes (LULCC) and their impacts, are the focus of this study. A new attribution method was developed and applied to observed data for investigating the interrelationships between climate variation and LULCC. Regional climate (temperature and precipitation) changes are attributed to climate variation and LULCC; LULCC is attributed to climate variation and human activities. Climate attribution analysis indicated a larger contribution ratio (based on comparison of standard deviations of each contributing factor-induced climate changes and that of total change)
\end{abstract}

This article is part of a Special Issue on "Regional Earth System Modeling" edited by Zong-Liang Yang and Congbin Fu.

X. Fan $\cdot$ Z. Ma $(\bowtie) \cdot$ Q. Yang $\cdot$ Y. Han

Key Laboratory of Regional Climate-Environment Research for Temperate East Asia, Institute of Atmospheric Physics, Chinese Academy of Sciences, Beijing 100029, China

e-mail: mazg@tea.ac.cn

X. Fan

e-mail: xingang.fan@wku.edu

Q. Yang

e-mail: yangqing@tea.ac.cn

Y. Han

e-mail: hanyh@tea.ac.cn

X. Fan • R. Mahmood

Meteorology Program, Department of Geography and Geology, Western Kentucky University, Bowling Green, KY 42101, USA

R. Mahmood

e-mail: rezaul.mahmood@wku.edu

Y. Han

University of Chinese Academy of Sciences, Beijing 100049, China

R. Mahmood

Kentucky Climate Center, Western Kentucky University, Bowling Green, KY 42101, USA 
from climate variation than from LULCC ( 0.95 from climate variation vs. 0.35 from LULCC) for variations in temperature. Impacts on precipitation indicated more spatial variations than those on temperature. The spatial variation of LULCC impacts on precipitation implied that human activities might have larger impacts on precipitation in the region's arid north than in its humid south. Using both leaf area index (LAI) and areal coverage of each of the major land types, LULCC attribution analysis suggested that LULCC observed in the 2000s resulted primarily from human activities rather than climate variations ( 0.99 contribution ratio from human activities vs. 0.26 from climate variation).

\section{Introduction}

Interactions between land use/land cover (LULC) change (LULCC) and regional climate variations have been found to be complicated, yet at the same time very important for environmental adaptation and management (Pielke 2005; Bonan 2008; Liu et al. 2008). Investigations are urgently needed, particularly, to study the effects of government policies and human activities that have been undertaken in an attempt to mitigate some of the impacts resulting from the degradation of the natural environment (e.g., Tao et al. 2004; Hvistendahl 2012). An example of these is the well-known Chinese government-funded Grain for Green Project (GFGP), which encourages the return of terracefarming croplands to forests/grasslands in order to restore their natural ecosystems (Tao et al. 2004). The GFGP project is widely adopted in the Loess Plateau region and throughout China. The regional climate of the Loess Plateau is mostly continental arid to semi-arid. Moreover, it has experienced a drying and warming trend since the 1970s (Ma and Fu 2006). These climatic conditions make the Loess Plateau one of the most sensitive ecological regions in China, which is fragile and susceptible to climate changes (Liang et al. 2008). This is the primary reason the region was selected as the initial location for the GFGP, and is also the region on which we focus our investigation.

In the accompanying study of Fan et al. (2014, FAN14 hereafter), the LULCC during the period 2001-09 over the Loess Plateau region (Fig. 1a) have been reported based on an analysis of both remotely sensed observations and governmental census data. In FAN14, it was revealed that a significant increase in both the spatial vegetation coverage and vigor of growth had occurred. The reported conversions among vegetation types derived from remotely sensed data correlated highly to census-reported changes. This was particularly true for forests, where a significant amount of changes were resulted from GFGP and other afforestation projects. The Loess Plateau ecosystem and its regional climate warrant more in-depth investigation due to the region's uniqueness as an area where both natural and human modifications intermingle (Jiao et al. 2005; Zhang et al. 2006; Cao et al. 2007; Liang et al. 2008).

It is well known that vegetation distribution is primarily determined by climatic and environmental factors such as temperature and precipitation, as well as elevation, accumulated sunshine, and winds (Zhang et al. 2006). Climate change has been found to affect ecosystems in many respects, including LULCC and changes in vegetation (Goward and Prince 1995; Theurillat and Guisan 2001). On the other hand, results also show the importance of LULC in land-surface-atmosphere interactions (Dirmeyer et al. 2010). It has been demonstrated that the state of LULC could impact mesoscale convective development and circulation, meso- and regional-scale heat and moisture fluxes, precipitation, and temperature (e.g., Clark and Arritt 1995; McPherson 2007; Mahmood et al. 2010). As a result, it is expected that LULCC would modify the existing nature of land-surfaceatmosphere interactions and, consequently, weather and climate. Many local-, regional-, and globalscale studies have demonstrated this assertion (e.g., Chase et al. 2000; Chen et al. 2012).

Afforestation may cause different impacts pertinent to various spatial and temporal scales, as well as having both localized and remote impacts. Some of the local impacts include both warming and cooling, as well as drying and wetting, all resulting from modifications to 
a

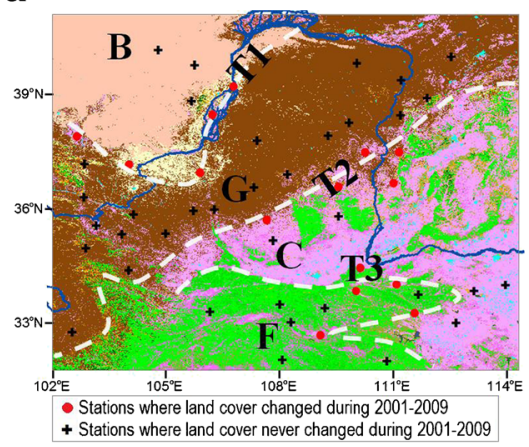

C

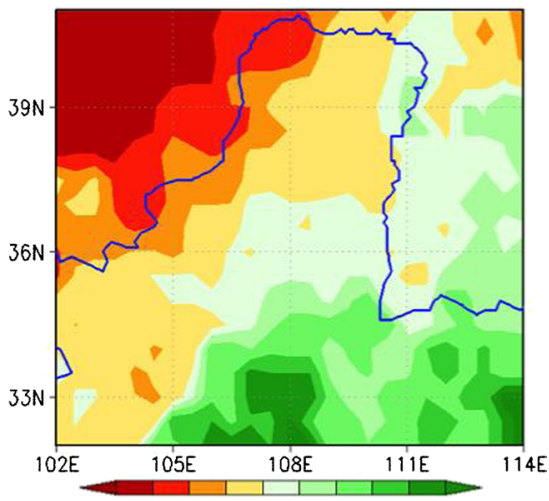

$20406080100120140160180200 \mathrm{~mm}$ b

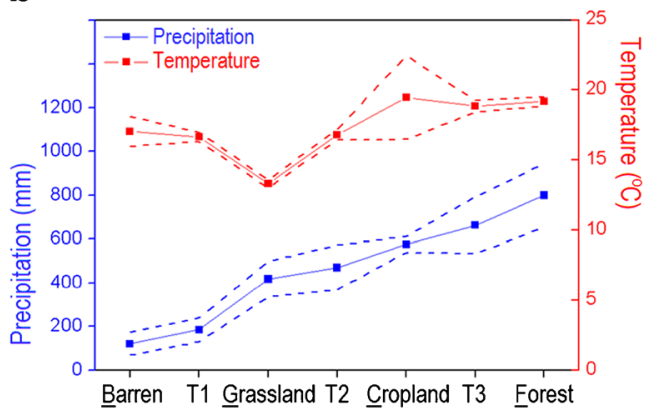

d

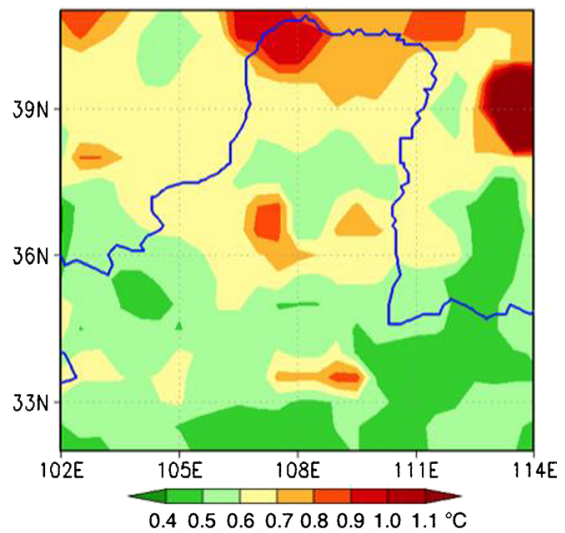

Fig. 1 a Primary land cover types and transition zones in the study area overlaid on a 2009 LULC map: $B$-Barren or sparsely vegetated; $G$ - Grassland; $C$ - Cropland; $F$-Forest; $T 1$ - Transition zone dominated by open shrublands; T2-Transition zone dominated by closed shrublands; T3-Transition zone dominated by woody savannah. Red dots mark the stations where land cover changed during 2001-09; black plus signs mark the stations where land cover remained unchanged during 2001-09; b 30-year (1961-90) averaged warm season (April-October) surface air temperature $\left({ }^{\circ} \mathrm{C}\right)$ and precipitation $(\mathrm{mm})$ for the four land-type zones (barren, grassland, cropland, and forest) and three transition zones (T1, T2, and T3); dashed lines indicate \pm 1 standard deviations; $\mathbf{c}$ standard deviation of warm-season precipitation $(\mathrm{mm})$; $\mathbf{d}$ standard deviation of warm-season surface air temperature $\left({ }^{\circ} \mathrm{C}\right)$

physical, chemical, and biological properties such as albedo, surface roughness, soil water capacity, carbon flux, and biomass productivity. Remote impacts include, for example, increased precipitation in downwind areas (Jiao et al. 2005). Large-scale afforestation may also increase the severity of water shortages in arid regions (Cao et al. 2007).

Therefore, climate and LULC interact and cause concurrent mutual impacts on each other while climate variations and LULCC also result from external forcings and human activities. However, these intermingling factors and interacting processes results in only one set of reality. It is always desirable but challenging to isolate and recognize the role of each individual factor or process so that applicable strategies may be devised toward a sustainable climate and environment. One widely used approach is numerical modeling using general circulation models (GCMs) in single-forcing sensitivity experiments. For example, Bonan (1997), Fu (2003), Pielke (2005), Pitman et al. (2009), and Avila et al. (2012) studied impacts of LULC as single forcing on climate simulations using GCMs. Kumar et al. (2013) devised a method to identify LULC impacts on climate from multiple 
GCM simulations. These studies have either prescribed LULCCs for sensitivity experiments or utilized difference of present and preindustrial LULC conditions to represent the LULCC, most commonly, cropland fractions (e.g., Noblet-Ducoudre et al. 2012). However, the attribution of the changes remains a challenge due to the limited resolution and capability of GCMs to take into consideration of the dynamically and concurrently changing LULC and climate, especially for the recent decade afforestation efforts and climate change in the study area of China.

Given that afforestation and its associated changes in LULC and regional climate have already taken place, this study is to: 1) analyze observed climate and LULC data to reveal their interrelationships; 2) devise a method to attribute: a) changes in LULC to either climate change and/or human activities (agricultural, afforestation/deforestation, etc.) and b) changes in regional climate to either natural climate variations and/or human activity-induced LULCC; and 3) apply the method to observational data directly to extract information about these changes.

\section{Data and methodology}

\subsection{Data}

In this study, we focus on the study area shown in Fig. 1a, which covers the same geographical area as in FAN14. Specifically, it encloses the latitude-longitude region of $\left(32-41^{\circ} \mathrm{N}, 102-\right.$ $114^{\circ} \mathrm{E}$ ) and encompasses roughly $112.2 \times 10^{4} \mathrm{~km}^{2}$ over the Loess Plateau. Following FAN14, Moderate Resolution Imaging Spectroradiometer (MODIS) LULC and leaf area index (LAI) data are used in this study, which were available from 2001 to 2009 at 1-km horizontal and 8day temporal resolutions (Strahler et al. 1999). The dimensionless LAI data indicate the amount of available leaf material and, thus, can be used as an indicator of the vigor of vegetative growth.

In addition, Normalized Difference Vegetation Index (NDVI) time series, derived from the Advanced Very High Resolution Radiometer (AVHRR) on board the National Oceanic and Atmospheric Administration (NOAA) polar-orbiting satellites, were also used (Goward et al. 1991). NDVI is an indicator of the vegetative greenness of an area and, therefore, changes in NDVI can reveal changes in vegetation. NDVI data were available from 1981 to 2006 at 8-km horizontal and 15-day temporal resolutions (Goward et al. 1991).

Station-observed precipitation and surface air temperature data, obtained from the China Meteorological Administration, were also used. For each station, its LULC type, LAI, and areal coverage of a particular LULC type is determined from the 1-km pixels within a distance of $25 \mathrm{~km}$ from the station. Specifically, LULC type for a station is assigned the dominant MODIS LULC type among the pixels; LAI uses the average LAI of the pixels; and areal coverage of any LULC type is represented by the number of pixels of that type.

\subsection{Interrelationship analysis}

FAN14 reported that the large increase in vegetation coverage recently observed on the Loess Plateau indicated the effects of both climatic and human influences. Similarly, regional climate variation may be influenced by both natural climatic fluctuations as well as human activities. Within the scope of this study, we focus only on human-induced LULCC as the human activity under consideration.

In order to analyze their interrelationship, and ideally to isolate the impacts of natural climatic variations and human-induced changes, we take a simple approach to extract information directly from observations. Here, we are dealing with two challenges in properly attributing the impacts, each with two contributing factors. 1) Climate variation attribution: climate variations are represented by temperature $(T)$ and precipitation $(P)$. The two contributing factors are natural climatic 
variations in $T$ and/or $P$, along with human-induced LULCC. 2) LULCC attribution: LULCCs are represented by changes in LAI or areal coverage. The two contributing factors are natural climate variations and human-induced changes. We tackle these two attributions using two different scenarios. The first focuses on climate variation attribution within different zones of LULC; the other focuses on LULCC attribution under different climate conditions.

Although the vegetative cover changed over the 9-year period 2001-09, an obvious pattern exists where major LULC types consistently dominated and were sustained in certain areas (Fig. 1a). According to the spatial distribution of these major LULC types, the study area can be divided into four primary zones as shown in Fig. 1a, where B is used for barren or sparsely vegetated areas, $\mathrm{G}$ for grasslands, $\mathrm{C}$ for croplands, and $\mathrm{F}$ for forests. The areas in between these four zones form the three transition zones $\mathrm{T} 1, \mathrm{~T} 2$, and $\mathrm{T} 3$ along the borders of $\mathrm{B}$ and $\mathrm{G}, \mathrm{G}$ and $\mathrm{C}$, and $\mathrm{C}$ and F, respectively. Transition zone $\mathrm{T} 1$ is primarily covered by open shrublands, T2 by closed shrublands, and T3 by woody savannah. According to FAN14, most of the changes in LULC occurred in these transition zones where the two major LULC coverages on either side of a transition zone advanced or retreated for a given year.

Also shown in Fig. 1a are the weather stations from which temperature and precipitation data were used in this study. Stations where LULC types remained unchanged throughout 2001-09 are marked by black plus signs, whereas those stations where LULC types did change, mostly along the transition zones, are marked by red dots.

\subsubsection{Climate variation attribution}

The attribution method of Kumar et al. (2013) avoided large number of sensitivity modeling experiments by comparing neighboring changing and non-changing LULC regions' responses to a same all-forcing experiment. However, only a representative cropland-change was used and the dynamical change of LULC and its interaction with climate was neglected due to the nature of prescribing the LULC in the GCMs (though the interactions between a given LULC and the atmosphere are considered in most climate models). The method proposed below takes into consideration of the reality that LULC change occurs concurrently with climate change, which intermingled with human interference.

If a large area is dominated by a certain vegetation type that never changes, we can infer that: 1) climatic conditions have been favorable for the vegetation's sustainability and the area's interannual climate variations have most likely fallen within their natural range. Otherwise, the land cover would have changed to adapt to any abrupt changes in climate; 2) if any substantial climate change occurs, it can be largely attributed to external factors that resulted in such climate variation, or, at a minimum, is not necessarily attributable to LULCC (since there is no LULC change). This inference applies to all four primary LULC zones. Using temperature as an example climate variable, the actual temperature can be expressed as:

$$
T=\bar{T}+T_{C}^{\prime}
$$

where $\bar{T}$ is the average climatic temperature and $T_{C}^{\prime}$ is the variation in temperature (subscript " $C$ " represents climate variation).

However, in areas where LULC did change, for example the transition zones, LULCC may have contributed to the climate in addition to natural climate variation. Thus, an additional term should be added to Eq. (1) to account for the variations due to LULCC ( $T_{L}^{\prime}$; $\operatorname{subscript~"~} L$ " represents LULCC): 


$$
T=\bar{T}+T_{C}^{\prime}+T_{L}^{\prime}
$$

Other factors such as local terrain or slope orientation may cause different local manifestation of a large-scale climate variation. However, at vegetation or human time-scales (a few tens or hundreds of years), these effects may be considered stationary and thus included in $\bar{T}$. As shown in Fig. 1b-d the variability (standard deviation) of 30-year (1961-90) warm-season (April-October) precipitation and surface air temperature, the changes of variability occur gradually and consistently across the major zones and the transition zones. Particularly for precipitation, the variability also follows the pattern of total annual precipitation distribution (ref. FAN14 Fig. 3). Thus, it may be reasonably assumed that the natural climate variation is either consistent or spatially continuous throughout the region (the study area) and any localized fluctuations may be neglected. We can infer rationally that the climate variation in a transition zone lies between that of the two neighboring zones. Therefore, the $T_{C}^{\prime}$ in Eq. (2) that corresponds to transition zone $\mathrm{T} 1\left(T_{C, T 1}^{\prime}\right)$, for example, can be estimated by averaging $T_{C}^{\prime}$ of the neighboring barren land zone $\mathrm{B}\left(T_{C, B}^{\prime}\right)$ and grassland zone $\mathrm{G}\left(T_{C, G}^{\prime}\right)$ from Eq. (1) as:

$$
T_{C, T 1}^{\prime}=\frac{1}{2}\left(T_{C, B}^{\prime}+T_{C, G}^{\prime}\right)
$$

As discussed in the next section, the utilization of standardized data further assures that the above inference and calculation is appropriate. A similar estimation applies to transition zones T2 and T3, but involving $T_{C}^{\prime}$ from grassland, cropland, and forest. Then, using Eq. (2), the variation of temperature due to LULCC $\left(T_{L}^{\prime}\right)$ can be estimated for each transition zone from the stations marked in red in Fig. 1a. Finally, the relative contributions from climate variation and LULCC can be estimated and measured by the following contribution ratios as defined using standard deviations (denoted by $\sigma$ ):

$$
\left\{\begin{array}{l}
r_{C}=\sigma_{T_{C}^{\prime}} / \sigma_{T} \\
r_{L}=\sigma_{T_{L}^{\prime}} / \sigma_{T}
\end{array}\right.
$$

where $r_{C}$ and $r_{L}$ represent the contribution ratios of climate variation and LULCC, respectively.

All of the above calculations, derived for temperature $(T)$, are readily applicable to precipitation $(P)$ as a climate variable.

\subsubsection{LULCC attribution}

Here we consider two situations: 1) if climate conditions remain constant, LULC and/or vegetation types will not change unless directly impacted by human-induced changes; 2) if the climate has changed, then any LULCC will be due to both human-induced changes and climate variations. Thus,

$$
L=\bar{L}+L_{H}^{\prime}+L_{C}^{\prime}
$$

where $L$ can be any LULC variable, such as LAI or areal coverage; $\bar{L}$ is its long-term average, which is assumed constant if the climate remains constant and no human intervention exists; $L_{H}^{\prime}$ and $L_{C}^{\prime}$ are changes in LULC due to human activities and climate variations, respectively. $L_{C}^{\prime}=0$ when climate conditions remain the same.

Climate-induced LULCC (i.e., $L_{C}^{\prime}$ ) should correlate with climate variables. From the analysis in FAN14 and below in Section 3.1, LULCC correlates with precipitation, while precipitation has a negative correlation with temperature. Even human-manipulated croplands 
are strongly related to precipitation, as agricultural activities in the Loess Plateau region rely significantly on precipitation availability. Therefore, $L_{C}^{\prime}$ may be estimated by first establishing a regression relationship between $L$ and the two climate variables $P$ and $T$, and then calculating $L_{C}^{\prime}$ from variations in $P$ and $T$ (i.e., $P_{C}^{\prime}$ and $T_{C}^{\prime}$ ). This procedure applies to all four primary LULC zones. In calculating the regression relationship for LAI, all stations in zones B, G, C, and $\mathrm{F}$ were used; however, for the areal coverage of an individual LULC type, only those stations within the same zone were used. Finally, $L_{H}^{\prime}$ can be estimated from Eq. (5). As was done in Eq. (4), the ratios of contribution from climate variation $\left(r_{C}\right)$ and human activities $\left(r_{H}\right)$ can be obtained from the standard deviations of $L_{C}^{\prime}, L_{H}^{\prime}$, and $L$.

\section{Results}

\subsection{Climate variations within areas of major LULC zones}

This subsection first discusses climate variations in the areas where LULC types were sustained and remaining stable throughout the study period. It is shown in Fig. 1 that precipitation gradually increases from Barren $\rightarrow \mathrm{T} 1 \rightarrow$ Grassland $\rightarrow \mathrm{T} 2 \rightarrow$ Cropland $\rightarrow$ $\mathrm{T} 3 \rightarrow$ Forest, which essentially represents a path curving from the northwest down to the south (see Fig. 1a). A distinct difference in precipitation of about 100-200 mm exists between each of the four primary LULC zones. The one-standard deviations indicated by the dashed lines also indicate that the variability experienced a gradual and consistent change across these zones. The average temperatures show that the grassland is the coolest zone, cooler even than the barren area, which also reflects the effect that the grass and associated wetter-than-barren climate had on its temperature. The variation in air temperature lies within a range of $1-2{ }^{\circ} \mathrm{C}$, except for the cropland zone, where a variation of more than $5{ }^{\circ} \mathrm{C}$ is recorded. It is primarily due to human interference that cropland encompasses such a wide region (Fig. 1a and d), leading to a larger overall variation.

In addition to the average climate, temporal variations in station observations were also analyzed. Standardized data (the mean subtracted and the result divided by the standard deviation) were used to focus on the analysis of climatic changes by eliminating impacts from latitude, elevation, and other localized factors. Figure 2 shows the time series of standardized warm season surface air temperature and annual precipitation, as averaged over the stations within each primary LULC zone for which the LULC type remained unchanged, along with the actual total areal coverage of each particular LULC type. As mentioned above in Section 2.2.1, the variations shown for the primary LULC zones are mostly due to the fluctuations of the climate itself and lie within the range of natural variation for each individual LULC type. Analysis of these variations may help us to better understand the attributions discussed below.

In the barren zone (Fig. 2a), temperature and precipitation show a clear inverse relationship, with a correlation coefficient $r=-0.75$ that passes the $95 \% t$-test confidence level. A very weak correlation exists between the total area of barren land and the precipitation, even though the actual total area contains contributions from human activities. These correlations imply that the total barren land area decreases (increases) when it is cool and moist (warm and dry) and favorable (unfavorable) for vegetative growth. In the grassland zone (Fig. 2b), the inverse relationship between temperature and precipitation is also clearly seen $(r=-0.75,99 \%)$. Although a drying trend occurred after 2003, the decreasing trend in the grassland area was much smaller, implying impacts from human interference. The relationship between the total area of grassland and the precipitation is thus positive but weak (further discussions are 
a

b
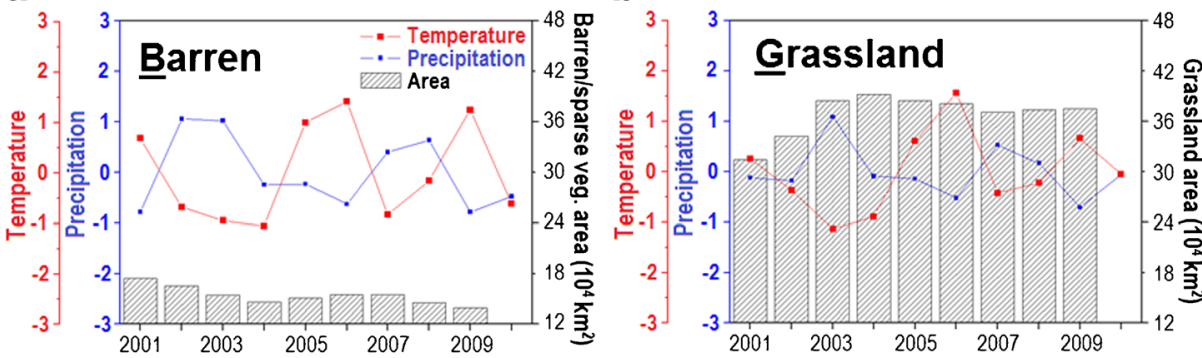

C

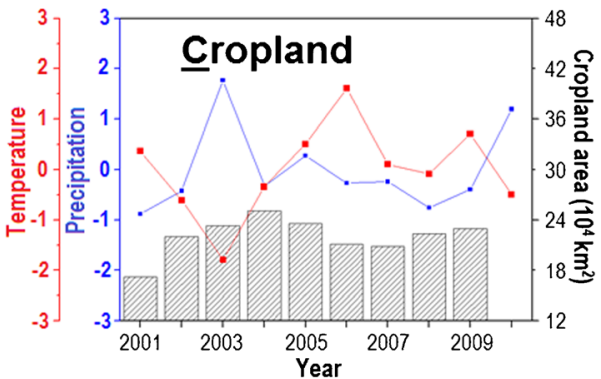

d

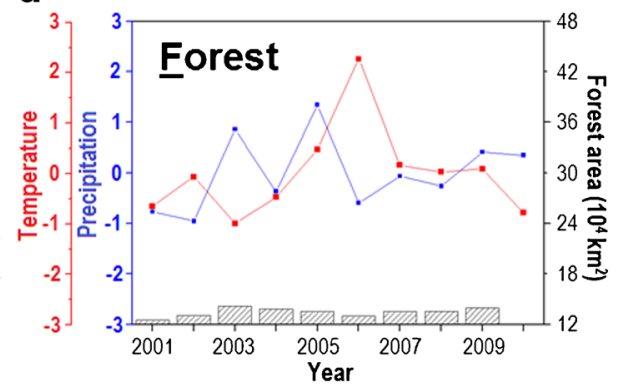

Fig. 2 Standardized mean surface air temperature (red line) and mean annual precipitation (blue line) of the stations within each of the primary land-type zones: a Barren, $\mathbf{b}$ Grassland, $\mathbf{c}$ Cropland, and $\mathbf{d}$ Forest. Bars show the total areal coverage $\left(10^{4} \mathrm{~km}^{2}\right)$ of each particular land type within the study area

presented below in Section 3.2). Croplands and forests are located in relatively warm and wet regions, and the inverse relationship between temperature and precipitation is weaker and insignificant in these zones. Cropland is a human-activity-dominated land type; however, in the Loess Plateau area, the rainfed farming has a strong dependence on local climate, with more precipitation necessary for the expansion of croplands. Therefore, a stronger positive relationship between total area of cropland and precipitation is seen $(r=0.45,90 \%$, Fig. $2 \mathrm{c})$. The forest zone displays similar variations as the croplands, but the correlation is not as significant (Fig. 2d).

Figure 3 shows the temperature and precipitation variations in the three transition zones. The results were averaged over the stations within each zone. The relative contributions from climate variation $\left(r_{C}\right)$ and LULCC $\left(r_{L}\right)$ are also marked in the figure. The variation in temperature for all three transition-zones shows a similar pattern (Fig. 3a-c). The deviations from climate ( $T_{C}^{\prime}$, long-dashed lines) closely follow the temperature, implying that the two LULC zones on either side of each transition zone have similar variations, which again confirms the assumption that the climate variation across the entire region is consistent or spatially continuous. The ratios of contribution from climate variation for the three transition zones are $r_{C}=0.92,0.91$, and 1.01 (an average of 0.95 ). The variation in temperature due to LULCC ( $T_{L}^{\prime}$, short-dashed lines) shows larger contributions in transition zones $\mathrm{T} 1$ and $\mathrm{T} 2$ than in $\mathrm{T} 3$, with $r_{L}=0.40,0.51$, and 0.14 , respectively. This suggests that in the forest zone of the warm south, the temperature is largely dominated by the established climate for the region (instead of LULC). Moreover, the impact from LULCC in the forested area is relatively small because the area was already dominated by dense vegetation, and changes in LULC were at a relatively smaller ratio to the forest. By 

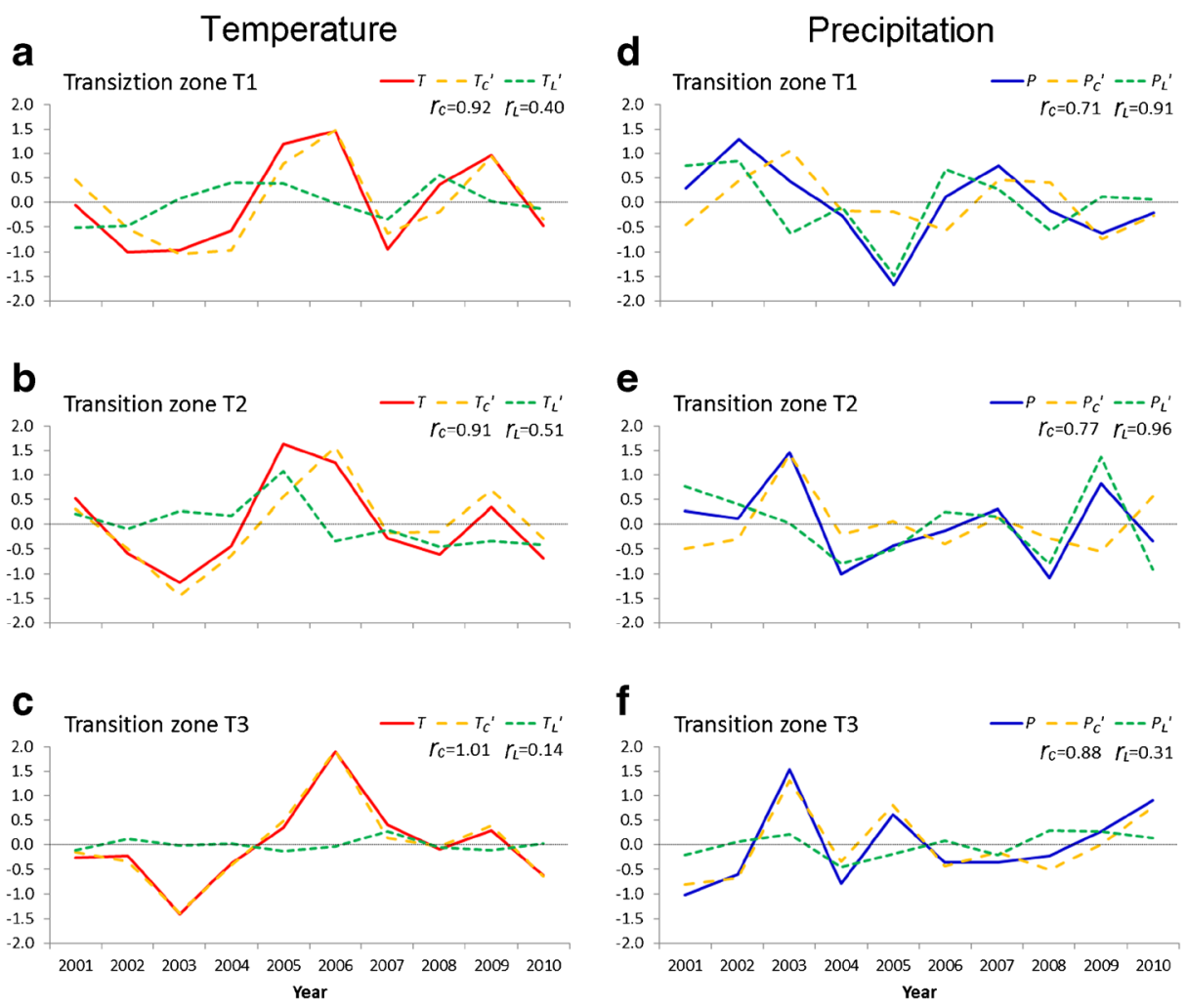

Fig. 3 Standardized annual mean temperature $(T$, left $)$ and precipitation $(P$, right $)$ for the three transition zones T1, T2, and T3. Long-dashed lines are climatic variations $\left(T_{C}^{\prime}, P_{C}^{\prime}\right)$ based on the variations observed from two neighboring land-type zones. Short-dashed lines are variations due to land-cover change $\left(T_{L}^{\prime}, P_{L}^{\prime}\right) . r_{C}$ and $r_{L}$ are the ratios of contributions (standard deviations)

comparing the four LULC types shown in Fig. 2, we see that the total forested area is also the smallest in the study area. For each transition zone, the sum of $r_{C}$ and $r_{L}$ may be greater than 1 , meaning that the standard deviations of the two contributing factors sum to a total greater than the standard deviation of the resulting temperature (or precipitation, discussed below). The reason for this is that the two contributing factors may sometimes work together to enhance the changes and other times offset one another, thereby cancelling out their individual effects (Fig. 3).

The variations in precipitation (Fig. $3 \mathrm{~d}-\mathrm{f}$ ) exhibit distinct patterns in the three transition zones, implying that the impact from the two contributing factors is more variable. The contribution from climate variation is smaller than for temperature, with $r_{C}=0.71,0.77$, and 0.88 , implying greater spatial variation in the northern arid zones than in the humid south, since climate contributions are obtained from two neighboring LULC zones. The contribution from LULCC resulted in $r_{L}=0.91,0.96$, and 0.31 in the three transition zones. Owing to the complex nature of precipitation, many factors may contribute to the change in precipitation apart from the two considered herein. Nonetheless, the difference in $r_{L}$ suggests that LULCC may have stronger impacts in the northern two arid and semi-arid transition zones than in the southern humid one. One possible reason is that any LULCC that occurs in less vegetated arid and semi-arid zones may modify evapotranspiration and associated latent heat partition more 
greatly than the densely vegetated forests and nearby woody savannahs in the southern humid Qingling Mountains.

\subsection{LULCC under similar climate conditions}

As pointed out by FAN14, vegetation distribution over the Loess Plateau closely follows the distribution of mean annual precipitation. Spatial correlations were calculated for the percentage of annual precipitation anomaly for each year from 2001 to 2009 and all the years from 1980 to 2010 in order to identify years that had similar patterns in precipitation variation. The time period was chosen to match the availability of LAI and NDVI data. The LAI data have been found to accurately reflect changes in vegetation and match well with satellite imagery (FAN14).

Fan et al. (2009) found that LAI highly correlates with ground-measured NDVI. As shown in Fig. 4a, AVHRR NDVI data spanned from 1980 to 2006, while MODIS LAI data were available from 2000 to 2009. During the overlapping years of 2000-06, the interannual variability of NDVI and LAI closely matched one another. Their strong relationships are shown in Fig. $4 \mathrm{~b}$ for the warm-season averaged LAI and NDVI. The exponential relationship shows a coefficient of determination $r^{2}=0.88$, passing a $99.9 \% t$-test confidence threshold. Therefore, NDVI can properly be used as a substitute for LAI when LAI data is not available, or vice versa.

Based on the results of a spatial correlation analysis, four pairs of years were identified as having high spatial correlation coefficients and similar distribution patterns for the anomaly of annual precipitation. These year-pairs were 1995/2008 (A), 1994/2002 (B), 2000/2005 (C), and 1996/2007 (D), which had spatial correlations of $r=0.68,0.67,0.64$, and 0.55 , respectively. Shown also in Fig. 4a are magnitudes of precipitation and temperature anomalies, with the four year-pairs marked. The magnitudes of the precipitation anomaly for the four year-pairs are comparable. The areal-averaged annual precipitation anomaly was negative for pairs A, B,

a

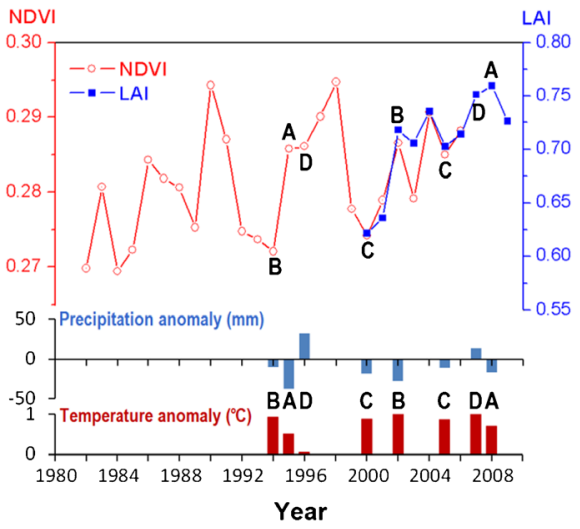

b

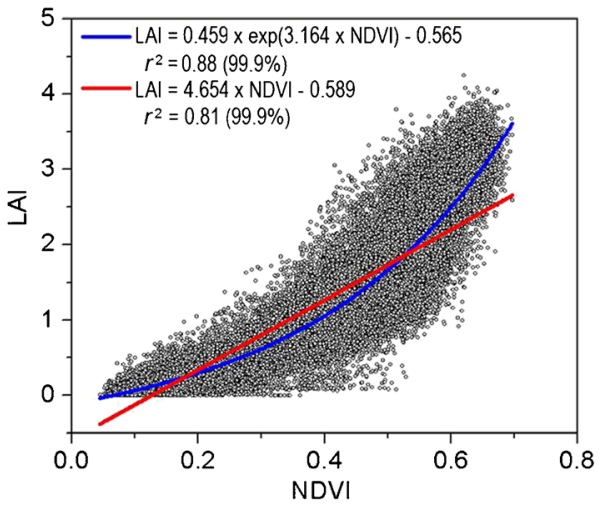

Fig. 4 a Time series of mean annual NDVI (1981-2006) and LAI (2000-09), both averaged over the study area. Four pairs of years that had similar precipitation distribution patterns and high spatial correlations are marked by A: $1995 / 2008, B: 1994 / 2002, C: 2000 / 2005$, and $D: 1996 / 2007$, along with the anomalies of mean annual precipitation $(\mathrm{mm})$ and surface air temperature $\left({ }^{\circ} \mathrm{C}\right)$ over the 8 years; $\mathbf{b}$ exponential and linear relationships of warm season (April-October) mean LAI vs. NDVI when both were available during 2000-06, with $r^{2}=0.88$ and 0.81 , respectively; both are significant at the $99.9 \%$ confidence level. (Sample size $N=76,832$ and LAI is interpolated to $0.1^{\circ} \times 0.1^{\circ} \mathrm{NDVI}$ pixels) 
and C, and positive for pair D; in the latter, 2007 was slightly drier than 1996. The magnitudes of the temperature anomaly within each pair were also alike, except for pair D, where 1996 was close to climatology but 2007 was about $1^{\circ} \mathrm{C}$ warmer. Thus, the two years in pair D exhibited different climatic conditions than the other three when temperature is taken into consideration. Both years were wetter and warmer than normal, but 2007 was relatively drier and warmer than 1996.

Figure 5 shows the spatial distributions of the annual precipitation anomaly for each yearpair, along with comparisons of monthly LAI, NDVI, and precipitation for the four year-pairs. It is indicated that the vegetation coverage for years during 2001-09 was, for the most part, greater than for years in the previous decade under similar climate conditions, particularly during the growing season (March through August). The monthly precipitation differences indicated no direct correlation with the LAI and/or NDVI changes. An exception was 2007, when compared to 1996. Due to the relatively wet and cool conditions in 1996, LAI experienced a rapid increase in June 1996, which resulted in the negative difference (Fig. 5d). When averaged over the entire warm season, the LAI in 2007 was nearly the same as in 1996. These overall increases in LAI further suggest human impacts on LULCC through the implementation of afforestation projects in the 2000s (ref. FAN14). On the other hand, even though the vegetative cover was greatly modified, the climate patterns demonstrate similarity to those of the previous decade. From this, we may conclude that climate plays a dominant role in the distribution of vegetation. Any feedback of vegetation to the climate is not obvious. Further in-depth analysis through the application of the LULCC attribution method described in Section 2.2.2 is thus deemed necessary for better understanding of their interrelationships.

The LULCC attribution method was applied to both LAI data and areal coverage data. The impact from climate variation $\left(L_{C}^{\prime}\right)$ was regressed from temperature and precipitation changes (standardized $T$ and $P$ were used). Figure 6 shows the results of this analysis. For LAI (Fig. 6ad), we see from both the regression equation $L_{C}^{\prime}=0.167 P-0.124 T+0.007$ and the $L_{C}^{\prime}$ curves that LAI has a positive relationship with precipitation and a negative relationship with temperature. The contribution ratio from climate variations $\left(r_{C}\right)$ lie in the $0.23 \sim 0.27$ range. The resultant contribution ratio from human-induced changes $\left(r_{H}\right)$ lies in the $0.89 \sim 1.07$ range. The fact that $r_{H}$ increases from Barren to Grassland to Cropland to Forest zones indicates that human activities had the greatest impact on LAI changes in the Forest zone. This is consistent with the findings in FAN14 and with respect to afforestation projects. These results suggest that although climate conditions largely dominate the determination of the type of LULC, the changes in LULC that occurred in the major land-type zones during the 2000s was largely human-induced.

An analysis based on the areal coverage demonstrates similar relationships as shown for LAI for the Cropland and Forest zones (Fig. $6 \mathrm{~g}-\mathrm{h}$ ). However, the area of barren land exhibited a positive relationship with precipitation (Fig. 6e), while the area of grassland showed a negative relationship (Fig. 6f). Nonetheless, the relative contributions of climate variation and human impact are consistent with the conclusions reached for LAI above.

\section{Summary and discussions}

FAN14 reported that the afforestation efforts that took place in China during the 1990s and 2000s have resulted in significant changes in vegetation coverage over the Loess Plateau. While the distribution of major vegetation zones is primarily determined by regional climate conditions, climatic variations have a clear impact on observed LULCC. Human activities, in 

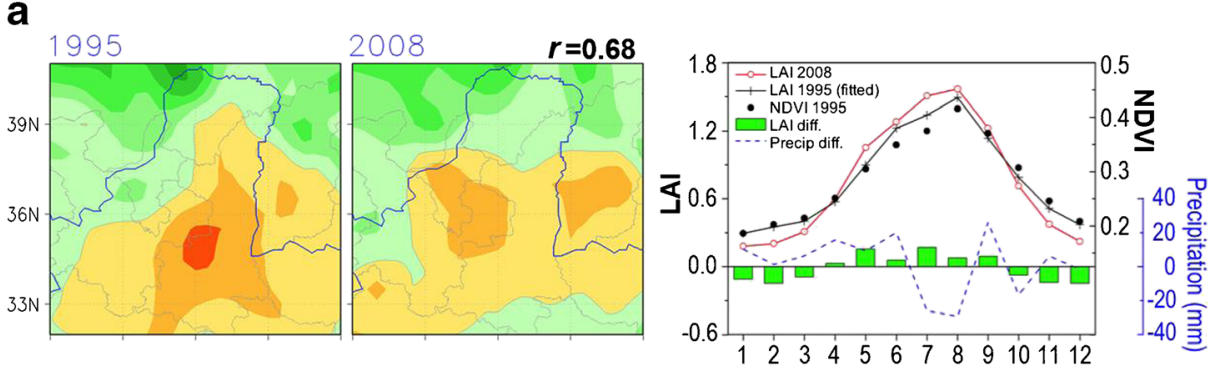

b
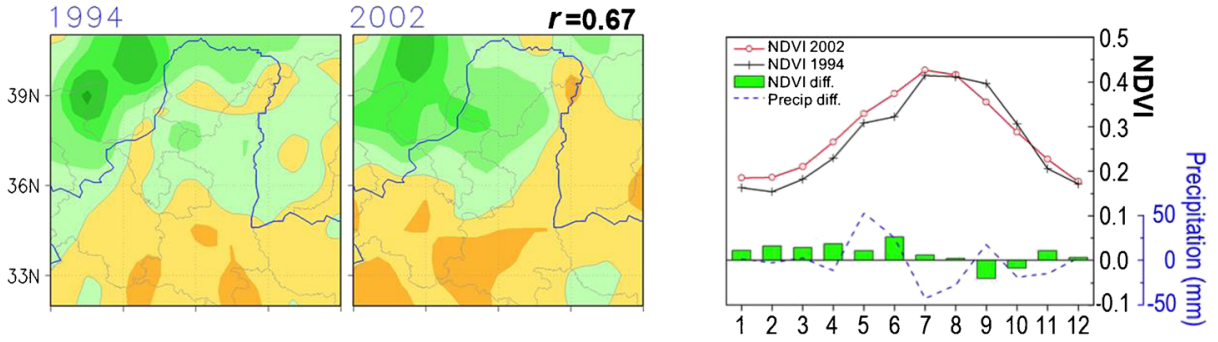

C
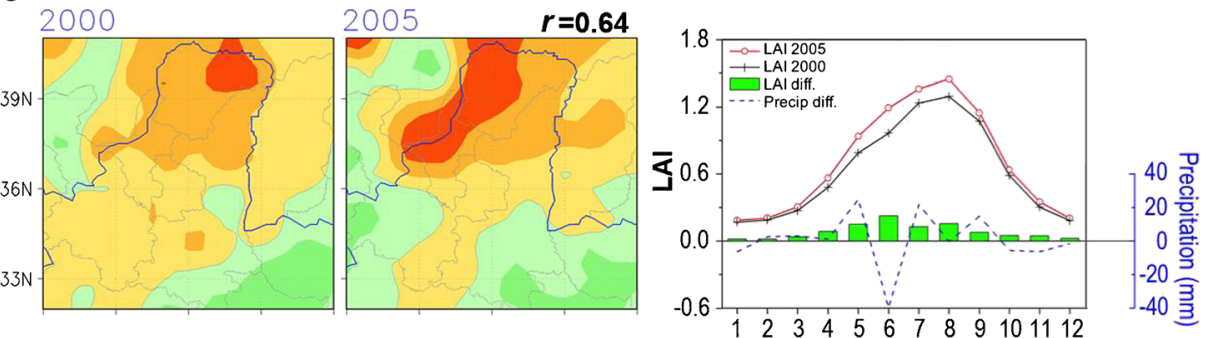

d
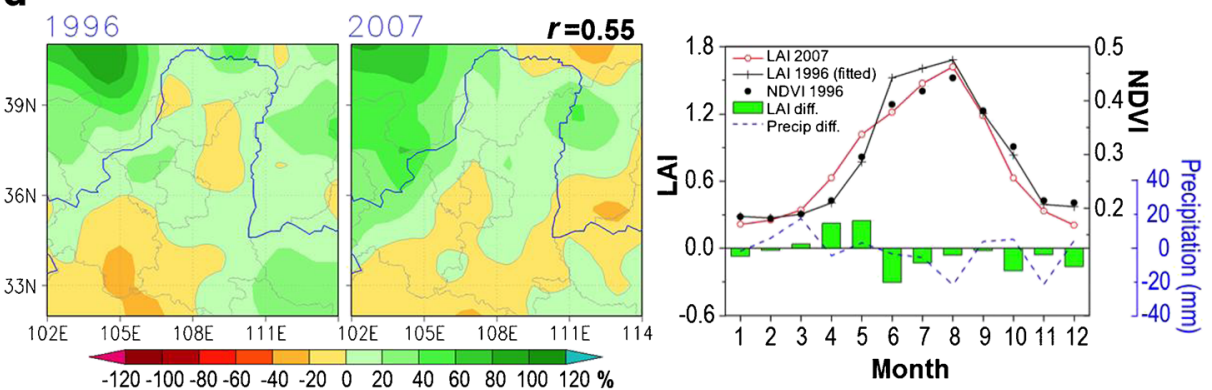

Fig. 5 Annual precipitation anomaly (shaded colors, in \%), along with monthly LAI and/or NDVI and their difference, as well as monthly precipitation difference $(\mathrm{mm})$, for four pairs of years that have high spatial correlations $(r)$ in annual precipitation anomaly: a 1995/2008 ( $r=0.68)$; b 1994/2002 ( $r=0.67)$; c 2000/2005 $(r=0.64)$; and d 1996/2007 $(r=0.55)$. In pairs a and d, LAI were fitted from NDVI data based on monthly exponential regression coefficients obtained from 2000 to 2006 data: $\mathrm{LAI}=0.459 \times \exp (3.164 \times \mathrm{NDVI})-0.565$. NDVI and LAI were available in pairs $\mathbf{b}$ and $\mathbf{c}$, respectively. Differences were calculated by subtracting the earlier year from the later year in each pair 
LAI

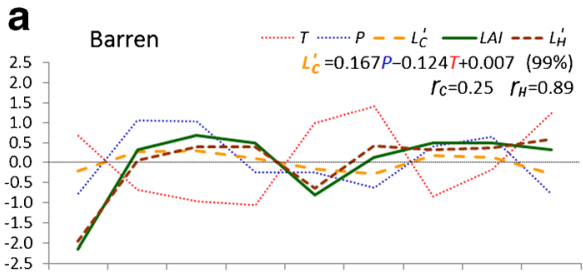

\section{b}
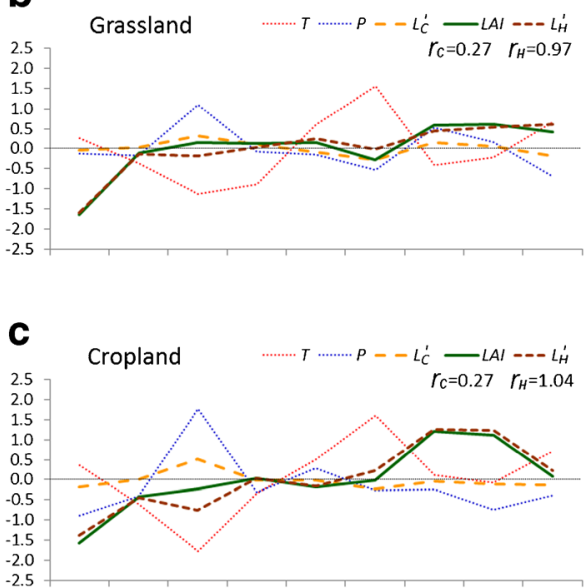

d

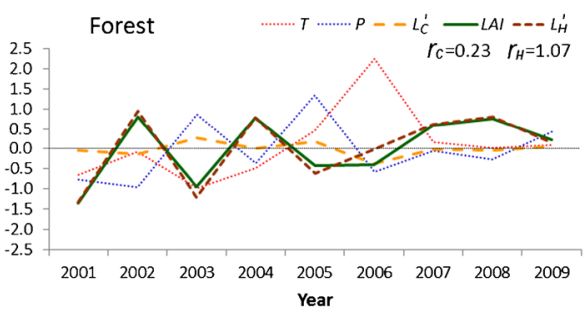

Area
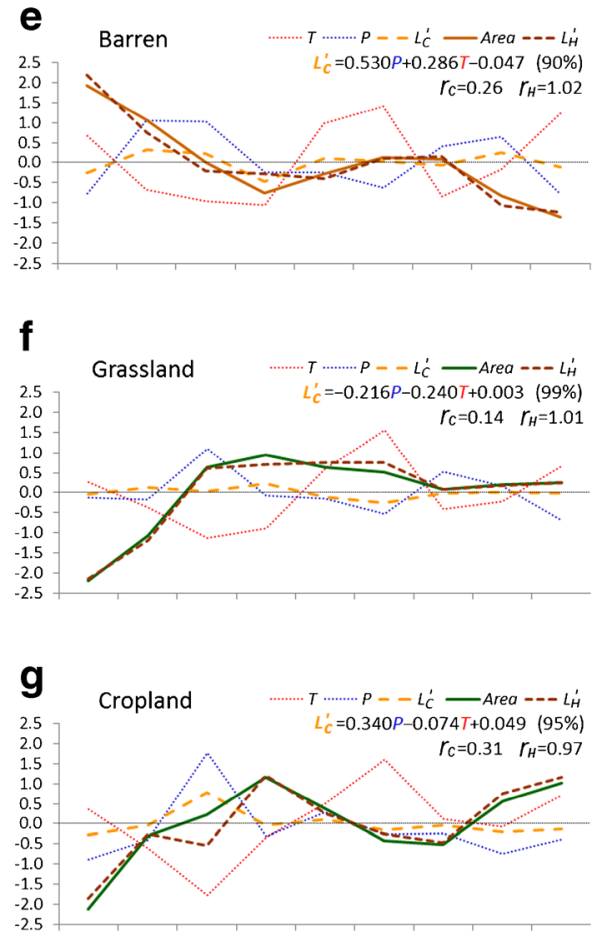

h

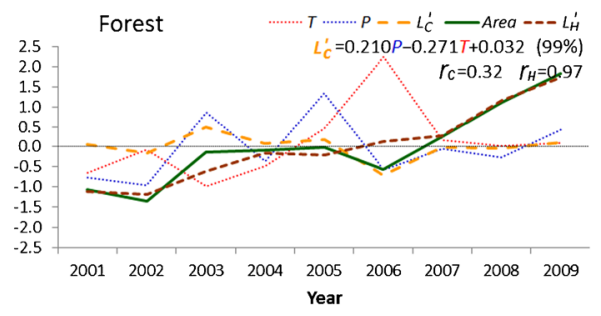

Fig. 6 Standardized warm season (April-October) LAI (left) and areal coverage (Area, right) over Barren, Grassland, Cropland, and Forest zones. Long-dashed lines are variations due to climate $\left(L_{C}^{\prime}\right)$, which is regressed from standardized precipitation ( $P$, blue-dotted line) and temperature ( $T$, red-dotted line). Regression for LAI was computed by using all available stations in the entire study area; while Area regression was computed by using all available stations within each land-type zone, where the areal coverage was estimated from the area surrounding each station within a radius of $25 \mathrm{~km}$ (100 km for Forest). Significance levels of the regressions from an $F$-test are given in parentheses. Short-dashed lines are variations due to human-induced land-cover change $\left(L_{H}^{\prime}\right) . r_{C}$ and $r_{H}$ are the ratios of contributions (standard deviations)

particular the afforestation/reforestation practices that are the focus herein, have contributed to a large portion of LULCC. These changes in LULC alter the underlying surface conditions of the atmosphere, eventually feeding back and having an impact on the climate. A question thus arose regarding the degree to which the currently observed climate is the result of its own natural fluctuation and how much results from the feedback of changed LULC conditions. To answer this question, an attribution method was devised and applied to observational data to 
determine the interrelationships between climate variation and LULCC, as well as to attempt the isolation of the impacts from climate variation to those from human-induced changes. From the results, the following conclusions were drawn:

1) Climate variations in areas of similar land use were slightly milder than in the transition zones in between. On the other hand, an analysis of historically similar climate years provides evidence for the existence of a clear trend in increasing vegetation cover and growth in the 2000 s relative to the previous decade. These demonstrate that climate variations exhibited in the primary LULC zones arise from mainly natural fluctuations. Changes in LULC under similar climate conditions primarily resulted from human activities.

2) Climate variations were attributed to a combination of its own natural interannual fluctuations and LULCC contributions. Contribution ratios indicated larger contributions from climate fluctuations (an average $r_{C}$ of 0.95) than from LULCC (an average $r_{L}$ of 0.35 ) for variations in temperature. Impacts on precipitation indicated larger spatial variations than on temperature. The spatial variation of LULCC impacts on precipitation implied that human activities might have had greater impacts on precipitation in the arid north than in the humid south, possibly due to the larger impacts on evapotranspiration and associated latent heat partitions over less vegetated arid regions than densely vegetated humid regions (e.g., forest and nearby woody savannahs).

3) LULCCs were attributed to a combination of climate variations and human activities. Both LAI and areal coverage of each of the primary LULC types were analyzed. The average relative contribution ratios from human activities (afforestation) were $r_{H}=0.99$, while the average contribution ratios from climate variations were just $r_{C}=0.26$. These suggest that the LULCCs of major land type zones occurred in the 2000s resulted primarily from human activities rather than natural climate variations, which is consistent with the findings reported in FAN14.

The present observation-based study suggests coupled and dynamic relationships between climate variations and LULCCs. One limitation of this study is that the limited observational record left some uncertainties in the results, particularly in the attribution analysis for the precipitation and the areal coverage of different land-cover types. We suggest that modeling study would be the next logical step to further understand the pathways and mechanisms of impacts of afforestation on climate.

Acknowledgements This research was supported by the National Basic Research Program of China (2012CB956201), the National Natural Science Foundation of China (41275085), the Knowledge Innovation Program of the Chinese Academy of Sciences (KZCX2-EW-202), and the Special Fund for Meteorological Scientific Research in Public Interest (GYHY201106028). Jeremy Krieger at the University of Alaska Fairbanks helped editing and proofreading the manuscript.

Open Access This article is distributed under the terms of the Creative Commons Attribution License which permits any use, distribution, and reproduction in any medium, provided the original author(s) and the source are credited.

\section{References}

Avila FB, Pitman AJ, Donat MG et al (2012) Climate model simulated changes in temperature extremes due to land cover change. J Geophys Res 117, D04108. doi:10.1029/2011JD016382 
Bonan GB (1997) Effects of land use on the climate of the United States. Clim Chang 37:449-486

Bonan GB (2008) Forests and climate change: forcings, feedbacks, and the climate benefits of forests. Science 320:1444-1449. doi:10.1126/science.1155121

Cao SX, Chen J, Chen L, Gao WS (2007) Impact of Grain for Green Project to nature and society in North Shaanxi of China. Sci Agric Sin 40:972-979, in Chinese

Chase TN, Pielke RA, Kittel TGF et al (2000) Simulated impacts of historical land cover changes on global climate in northern winter. Clim Dyn 16:93-105

Chen GS, Notaro M, Liu Z, Liu Y (2012) Simulated local and remote biophysical effects of afforestation over the southeast United States in boreal summer. J Clim 25:4511-4522. doi:10.1175/JCLI-D-11-00317.1

Clark CA, Arritt RW (1995) Numerical simulations of the effect of soil moisture and vegetation cover on the development of deep convection. J Appl Meteorol 34:2029-2045

Dirmeyer PA, Niyogi D, De Noblet-Ducoudré N et al (2010) Impacts of land use change on climate. Int J Climatol 30:1905-1907. doi:10.1002/joc.2157

Fan L, Gao Y, Bruck H, Bernhofer C (2009) Investigating the relationship between NDVI and LAI in semiarid grassland in Inner Mongolia using in situ measurements. Theor Appl Climatol 95:151-156. doi:10.1007/ s00704-007-0369-2

Fan X, Ma Z, Yang Q et al (2014) Land use/land cover changes and regional climate over the Loess Plateau during 2001-2009. Part I: observational evidence. Clim Chang (this issue)

Fu C (2003) Potential impacts of human-induced land cover change on East Asia monsoon. Glob Planet Chang 37:219-229

Goward SN, Prince SD (1995) Transient effects of climate on vegetation dynamics: satellite observations. J Biogeogr 22:549-564

Goward SN, Markham B, Dye DG et al (1991) Normalized difference vegetation index measurements from the advanced very high resolution radiometer. Remote Sens Environ 35(2-3):257-277

Hvistendahl M (2012) Turning over a new leaf in China's forests: a massive redistribution of land use rights aims to boost afforestation and sustainable forestry. Science 337(6090):26-27. doi:10.1126/science.337.6090.26

Jiao F, Wen ZM, Li R (2005) Analysis on environment effects of the returning farmland into forest and grassland on the Loess Plateau. Res Soil Water Conserv 12(1):26-29 (in Chinese)

Kumar S, Dirmeyer PA, Merwade V et al (2013) Land use/cover change impacts in CMIP5 climate simulations: a new methodology and 21st century challenges. J Geophys Res Atmos 118:6337-6353. doi:10.1002/jgrd. 50463

Liang L, Lu SH, Shang LY (2008) Numerical simulation of effect of Loess Plateau vegetation change on local climate. Plateau Meteorol 27(2):293-300 (in Chinese)

Liu J, Li S, Ouyang Z et al (2008) Ecological and socioeconomic effects of China's policies for ecosystem services. Proc Natl Acad Sci U S A 105(28):9477-9482. doi:10.1073/pnas.0706436105

$\mathrm{Ma}$ Z, Fu C (2006) Some evidences of drying trend over North China from 1951 to 2004. Chin Sci Bull 51(23): 2913-2925. doi:10.1007/s11434-006-2159-0

Mahmood R, Pielke RA Sr, Hubbard KG et al (2010) Impacts of land use land cover change on climate and future research priorities. Bull Am Meteorol Soc 91:37-46

McPherson RA (2007) A review of vegetation-atmosphere interactions and their influences on mesoscale phenomena. Progr Phys Geogr. doi:10.1177/0309133307079055

Noblet-Ducoudre ND et al (2012) Determining robust impacts of landuse-induced land cover changes on surface climate over North America and Eurasia: results from the first set of LUCID experiments. J Clim 25:32613281. doi:10.1175/JCLI-D-11-00338.1

Pielke RA (2005) Land use and climate change. Science 310:1625-1626

Pitman AJ et al (2009) Uncertainties in climate responses to past land cover change: first results from the LUCID intercomparison study. Geophys Res Lett 36, L14814. doi:10.1029/2009GL039076

Strahler A, Muchoney D, Borak J et al (1999) MODIS Land Cover and Land-Cover Change. MODIS Land Cover Product Algorithm Theoretical Basis Document (ATBD) Version 5.0. Center for Remote Sensing, Department of Geography, Boston University, Boston, MA

Tao R, Xu ZG, Xu JT (2004) Grain for Green Project, grain policy, and sustainable development. Soc Sci China 6:25-38 (in Chinese)

Theurillat JP, Guisan A (2001) Potential impact of climate change on vegetation in the European Alps: a review. Clim Chang 50:77-109

Zhang JT, Ru WM, Li B (2006) Relationships between vegetation and climate on the Loess Plateau in China. Folia Geobot 41:151-163 